\title{
CARACTERÍSTICAS DA EVIDENCIAÇÃO DA FASE DE PESQUISA E DESENVOLVIMENTO DE ATIVOS INTANGÍVEIS NAS COMPANHIAS DE CAPITAL ABERTO BRASILEIRAS
}

\section{CHARACTERISTICS OF DISCLOSURE OF RESEARCH AND DEVELOPMENT PHASE OF INTANGIBLE ASSETS IN BRAZILIAN OPEN CAPITAL COMPANIES}

\author{
Letícia dos Santos Barsch ${ }^{1}$ \\ Universidade Federal de Santa Catarina \\ leticia.barsch@gmail.com
}

\author{
Maíra Melo de Souza \\ Universidade Federal de Santa Catarina \\ mairameloufsc@gmail.com
}

\begin{abstract}
RESUMO
Esta pesquisa objetivou identificar as características da evidenciação da fase de pesquisa e desenvolvimento de ativos intangíveis nas companhias de capital aberto brasileiras. Para alcançar o objetivo proposto, utilizou-se uma Lista de Verificação com base nos requisitos estabelecidos pelo CPC 04 (R1), com uma amostra de 36 companhias de capital aberto. Os resultados demonstram que a média do nível de evidenciação apresentou um resultado de $24,31 \%$. Percebe-se que as companhias que compuseram a amostra deste estudo pouco divulgaram informações a respeito dos detalhamentos e composições dos gastos com pesquisa e desenvolvimento. Destacam-se os seguintes pontos: i) qual intangível as companhias esperam que sejam desenvolvidos a partir das pesquisas realizadas; ii) como o desenvolvimento dos intangíveis irá gerar benefícios econômicos futuros; e iii) evidenciação da separação dos gastos com pesquisa e desenvolvimento. Constata-se que a evidenciação da fase de pesquisa e desenvolvimento de ativos intangíveis ainda é baixa no Brasil.
\end{abstract}

Palavras-chave: Pesquisa e desenvolvimento. Intangíveis gerados internamente. Evidenciação. Características.

\begin{abstract}
This research aimed to identify the characteristics of the disclosure of the research and development phase of intangible assets in Brazilian public companies. To achieve the proposed objective, a Checklist was used based on the requirements established by CPC 04 (R1), with a sample of 36 publicly traded companies. The results show that the average level of disclosure presented a result of $24.31 \%$. It can be seen that the companies that composed the sample of this study didn't divulge information about the details and compositions of the expenses with research and development. The following points stand out: i) which intangible companies expect to be developed based on the research carried out; ii) how the development of intangibles will generate future economic benefits; and iii) evidence of the separation of research and development spending. It is observed that the disclosure of the research and development phase of intangible assets is still low in Brazil.
\end{abstract}

Keywords: Research and Development. Intangibles generated internally. Disclosure. Characteristics.

\footnotetext{
${ }^{1}$ Letícia dos Santos Barsch - Universidade Federal de Santa Catarina Campus Reitor João David Ferreira Lima - Florianópolis - Santa Catarina - Brasil. 


\section{INTRODUÇÃO}

O mundo vive em um período no qual os meios digitais e as inovações predominam no meio social. A partir desse progresso, em virtude das novas tecnologias, da informática e também das telecomunicações, as companhias precisam estar dispostas a se habituar e mudar a sua forma de administrar e gerenciar as suas tomadas de decisões. Fazendo parte desse sistema corporativo, a contabilidade também passa por diversas mudanças, tanto na sua forma de reconhecimento quanto na evidenciação do patrimônio das companhias (CARLOS FILHO et al., 2014). Neste contexto, dentre os assuntos contábeis que são julgados difíceis e que exigem grande atenção, estão os ativos intangíveis.

Devido à difícil caracterização do conceito e também pela hesitação em relação à mensuração e reconhecimento, Schmidt e Santos (2009) consideram os ativos intangíveis como a classe mais complexa das discussões da teoria contábil. Para Hoss et al. (2010), o fato de contabilizar algo que não é material, já se torna algo difícil, por se tratar de um processo que não é usual, devendo avaliá-los em todas séries temporais (passado, presente e futuro).

Em 28 de dezembro de 2007 foi publicada a Lei n. 11.638 que incluiu o subgrupo intangível na contabilidade brasileira. Haja vista a magnitude dessa classe, em 2008, o Comitê de Pronunciamentos Contábeis (CPC) emitiu o pronunciamento contábil CPC 04, que trata de Ativo Intangível, posteriormente em 2010, publicou a sua revisão, passando a ser intitulado CPC 04 (R1).

A alteração realizada pela Lei n. ${ }^{\circ}$ 11.638/2007, inserindo o intangível no Balanço Patrimonial das companhias, bem como a publicação do CPC 04 (R1) normatizando o tema, contribuiu muito para a contabilidade brasileira, pois antes os ativos intangíveis eram evidenciados como ativo diferido, ou mesmo como ativo imobilizado, em alguns casos. Assim, as alterações promovidas na legislação brasileira promovem um grande avanço na qualidade da divulgação contábil.

O pronunciamento CPC $04(\mathrm{R} 1)$ estabelece as orientações necessárias para mensurar e reconhecer os tipos existentes de ativos intangíveis identificáveis, abrangendo tanto aqueles que são passíveis de registro quando adquiridos, como aqueles que são gerados internamente, estabelecendo para estes últimos os fatores que precisam ser atendidos para reconhecimento na contabilidade.

Em relação aos ativos intangíveis gerados internamente, os gastos relacionados podem ser utilizados para a criação de novos produtos, como também para melhorar os já existentes e apresentam a característica capaz de gerar benefícios econômicos futuros para a entidade 
(SCHMIDT; SANTOS, 2009). O CPC 04 (R1, 2010), em seu item 51, mostra que a tarefa de avaliar este tipo de intangível é complicada, por se tratar de um processo incerto, é difícil afirmar que determinado gasto irá gerar benefícios econômicos futuros para a entidade e se o mesmo pode ser mensurado com confiabilidade.

De acordo com o CPC 04 (R1, 2010), as fases de pesquisa e desenvolvimento de ativos intangíveis possuem aspectos distintos. $\mathrm{Na}$ fase de pesquisa, por se tratar apenas de uma indagação inicial e com uma subjetividade elevada em relação aos valores atribuídos nesta fase, os gastos internos com pesquisa são tratados como despesa do período. Já na fase de desenvolvimento, se a empresa demonstrar que estes gastos se enquadram nos aspectos propostos pelo CPC 04 (R1), estes são ativados como intangíveis, caso contrário serão enquadrados como despesa do período (MARTINS et al., 2013).

Assim, espera-se das companhias de capital aberto brasileiras a evidenciação da fase de pesquisa e da fase de desenvolvimento de maneira adequada, para que os usuários das demonstrações contábeis tenham a possibilidade de distinguir e analisar o que há publicado e para atender a legislação vigente no Brasil.

A evidenciação contábil é considerada um processo de grande importância na contabilidade, pois pode ser compreendida como um componente da transparência como um todo na gestão das entidades (AVELINO; PINHEIRO; LAMOUNIER, 2012). E se tratando de um tema de considerável complexidade como é o caso dos ativos intangíveis gerados internamente, a evidenciação contábil se torna um fator com potencial de afetar a conclusão tomada pelos usuários da contabilidade, tanto externos quanto internos.

Com base no exposto elaborou-se o seguinte problema de pesquisa: Quais as características da evidenciação da fase de pesquisa e desenvolvimento de ativos intangíveis gerados internamente nas companhias de capital aberto brasileiras? O objetivo da presente pesquisa é identificar as características da evidenciação da fase de pesquisa e desenvolvimento de ativos intangíveis gerados internamente nas companhias de capital aberto brasileiras.

A realização desta pesquisa justifica-se considerando a complexidade que envolve o reconhecimento dos ativos intangíveis gerados internamente, bem como a importância social e econômica que a transparência das informações contábeis representa para o Brasil.

É importante salientar que o presente trabalho se delimita a análise dos setores de atividades de tecnologia da informação, química, telecomunicações, bens industriais e saúde (medicamentos, produtos de limpeza, produtos de uso pessoal, medicamentos e outros produtos, serviços médicos hospitalares). Possuindo como foco central a análise dos gastos com ativos intangíveis desenvolvidos internamente por companhias pertencentes a estes segmentos. $\mathrm{O}$ 
motivo da análise de tais ramos justifica-se pelo fato dos mesmos possuírem uma tendência a possuir ativos intangíveis.

\section{REFERENCIAL TEÓRICO}

Neste tópico está exposta a base teórica que fundamenta esta pesquisa, englobando os seguintes temas: ativo intangível gerado internamente, evidenciação contábil e os estudos semelhantes.

\subsection{ATIVO INTANGÍVEL GERADO INTERNAMENTE}

De acordo Rodrigues, Elias e Campos (2014), as atividades relacionadas a pesquisa e ao desenvolvimento são encarregadas por fornecer conhecimento e inovação de acordo com os produtos ou serviços que são oferecidos no mercado.

Neste contexto, entre os meios existentes de se poderem evidenciar os ativos intangíveis, podem-se citar aqueles gerados pelas próprias empresas. (SCHMIDT; SANTOS, 2009). Os ativos intangíveis gerados internamente podem ser classificados como despesas, quando não atendem aos critérios de reconhecimento expostos pelo CPC 04 (R1, 2010), ou como um ativo, neste caso quando atendem aos critérios e fatores exigidos pelo CPC 04 (R1, 2010) para seu reconhecimento como ativo.

Para atender as determinações do CPC 04 (R1, 2010), primeiramente deve-se separar a geração do ativo intangível em fase de pesquisa e fase de desenvolvimento, pois, de acordo com a referida norma, a fase de pesquisa deve ser reconhecida como despesa do período, já a fase de desenvolvimento, desde que atenda aos fatores exigidos pelo pronunciamento contábil CPC 04 (R1, 2010), poderá ser reconhecida como ativo intangível.

Para melhor entendimento, o CPC $04(\mathrm{R} 1,2010)$ define pesquisa como a aplicação inicial e idealizada com a perspectiva de obter novo conhecimento sobre algo e desenvolvimento como o destino dessa aplicação a projetos que possam gerar benefícios econômicos futuros.

$\mathrm{Na}$ fase de pesquisa, os valores gastos não devem ser reconhecidos como ativo, sendo incorridos somente como despesa do período. Em seu item 55, o CPC 04 (R1, 2010) justifica que durante esta fase, as empresas não estão habilitadas a mostrar que estes gastos gerarão benefícios futuros.

Já na fase de desenvolvimento, por ser mais avançada e possuir um maior grau de certeza quanto à geração de benefícios econômicos futuros, os gastos deverão ser ativados no grupo de 
intangíveis, desde que a empresa consiga demonstrar que atende aos seguintes requisitos (caso contrário, será reconhecido como despesa do período assim como os gastos com pesquisa):

a) Viabilidade técnica para concluir o ativo intangível de forma que ele seja disponibilizado para uso ou venda;

b) Intenção de concluir o ativo intangível e de usá-lo ou vendê-lo;

c) Capacidade para usar ou vender o ativo intangível;

d) Forma como o ativo intangível deve gerar benefícios econômicos futuros. Entre outros aspectos, a entidade deve demonstrar a existência de mercado para os produtos do ativo intangível ou para o próprio ativo intangível ou, caso este se destine ao uso interno, a sua utilidade;

e) Disponibilidade de recursos técnicos, financeiros e outros recursos adequados para concluir seu desenvolvimento e usar ou vender o ativo intangível; e

f) Capacidade de mensurar com confiabilidade os gastos atribuíveis ao ativo intangível durante seu desenvolvimento (CPC 04 R1, 2010, p. 16).

Esse tratamento do pronunciamento contábil CPC 04 (R1, 2010) talvez tenha relação com o fato dos intangíveis possuírem uma subjetividade em relação à alocação dos gastos que realmente foram ocorridos em função do seu desenvolvimento.

Essa percepção está alinhada ao entendimento de Schmidt e Santos (2009) que ressaltam que os ativos intangíveis por si só são uma classe muito complexa, sendo considerada uma das maiores discussões da Teoria da Contabilidade, por ser difícil de ser definida, gerando dúvidas em relação a sua mensuração.

Em adição, as pesquisas de Dahmash, Durand e Watson (2009) e Oliveira, Rodrigues e Craig (2010) constataram que os investidores australianos e portugueses, respectivamente, levam em consideração as informações divulgadas sobre os ativos intangíveis no momento de atribuir preço a ação, o que demonstra sua relevância para os investidores na tomada de decisão. Diante do exposto, percebe-se a importância da adequada evidenciação dos ativos intangíveis, de modo a proporcionar informações fidedignas aos usuários externos.

\subsection{EVIDENCIAÇÃO CONTÁBIL}

A evidenciação contábil, que traduzido do inglês quer dizer disclosure, nada mais é do que divulgar informações (BEUREN; ANGONESE, 2015). A contabilidade apresenta como um de seus propósitos fornecer aos seus usuários informações que sejam verídicas e confiáveis, usando como meio para chegar a esse objetivo a evidenciação (PEIXOTO; MALAQUIAS, 2012).

De acordo com Iudícibus (2015), no Brasil, em várias situações a evidenciação é tratada como uma expressão de sentido semelhante às notas explicativas, entretanto este ato em si é 
relatado nos próprios relatórios formais, existindo outras formas possíveis de evidenciação. $\mathrm{O}$ autor cita como exemplos de meios de divulgação: demonstrações, notas explicativas, quadros e demonstrativos suplementares divulgados pelas empresas, dentre outros.

Iudícibus (2015) ainda complementa que a evidenciação está ligada com o objetivo da contabilidade que é trazer informações diferenciadas para todos os tipos de usuários. Corroborando com esta concepção, Rolim, Lemes e Tavares (2010) entendem que a evidenciação é o próprio objetivo da contabilidade, mas com a preocupação da qualidade em que as informações estão sendo divulgadas.

Cova (2008) aponta que a evidenciação procura pela transferência das informações contábeis, levando em maior consideração àquelas que possuem maiores ameaças e repercussão nos negócios. Hendriksen e Van Breda (2010) afirmam que para isto, a informação precisar estar devidamente adequada, justa e completa.

Avelino, Pinheiro e Lamounier (2012) apontam que divulgar as informações é um ato imprescindível para que os usuários externos saibam o posicionamento da empresa, se conscientizando que esta atue dentro dos limites considerados aceitáveis pela legislação, podendo reduzir as irregularidades e fraudes. Os autores ainda afirmam que depois da publicação do CPC 04 (R1) houve grande exigência para que haja uma melhor evidenciação dos ativos intangíveis.

Abordando os ativos intangíveis gerados internamente Martins et al. (2013) manifestam que os gastos relacionados a fase de desenvolvimento devem ser objetos de evidenciação detalhada, haja visto que para ativar os valores desta fase é necessário mensurar se este gerará benefícios futuros.

Nesta concepção, é possível afirmar que a evidenciação é um ato de grande relevância dentro da contabilidade, considerando que quanto maior for o nível de divulgação das informações nos relatórios contábeis melhor será o nível de entendimento e percepção dos usuários externos.

\subsection{ESTUDOS SEMELHANTES}

Para levantamento dos trabalhos similares a esta pesquisa, foi realizado um levantamento de estudos que fossem semelhantes ao objetivo almejado. Através das bases de dados Scientific Periodicals Electronic Library (SPELL), Google Acadêmico e dos Congressos USP de Controladoria e Contabilidade e Congresso Anpcont, foram encontrados alguns estudos análogos, que foram identificados a partir das seguintes palavras-chave de busca: ativo 
intangível, Intangible Assets, intangível em desenvolvimento, pesquisa e desenvolvimento e intangível gerado internamente.

No Quadro 1 estão expostas as pesquisas que se assemelham a este estudo. Foram encontrados 11 trabalhos, publicados entre os períodos de 2012 a 2016, que puderam embasar a referida pesquisa. No referido Quadro estão apresentados os autores com respectivas datas de publicação, o objetivo e período analisado do estudo seguido dos resultados demonstrados de forma sintética.

Quadro 1 - Pesquisas Semelhantes

\begin{tabular}{|c|c|c|c|}
\hline Autores & Local de Publicação & Objetivo e período analisado & Resultados \\
\hline $\begin{array}{l}\text { Dahmash, } \\
\text { Durand } \\
\text { Watson } \\
(2009)\end{array}$ & $\begin{array}{l}\text { The British Accounting } \\
\text { Review. }\end{array}$ & 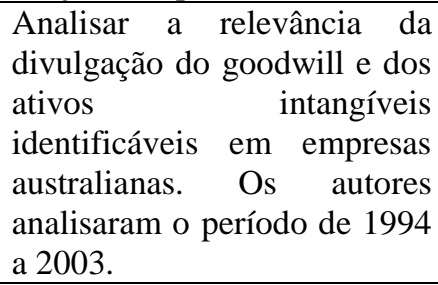 & $\begin{array}{l}\text { Os autores verificaram que as } \\
\text { informações divulgadas pelas } \\
\text { empresas sobre os intangíveis } \\
\text { identificáveis tendem a ser em } \\
\text { maior quantidade quando } \\
\text { comparadas as informações } \\
\text { divulgadas sobre o goodwill. }\end{array}$ \\
\hline $\begin{array}{l}\text { Oliveira, } \\
\text { Rodrigues e } \\
\text { Craig }(2010)\end{array}$ & $\begin{array}{l}\text { The British Accounting } \\
\text { Review. }\end{array}$ & $\begin{array}{l}\text { O objetivo do trabalho foi de } \\
\text { analisar a relevância dos } \\
\text { ativos } \\
\text { identificáveis e do goodwill } \\
\text { evidenciados rangíveis } \\
\text { demonstrações contábeis de } \\
\text { empresas portuguesas. O } \\
\text { período de análise foi dentre } \\
1998 \text { a 2008. }\end{array}$ & $\begin{array}{l}\text { Os autores constataram que no } \\
\text { valor total os ativos intangíveis } \\
\text { identificáveis são relevantes. } \\
\text { Entretanto, as despesas com } \\
\text { Pesquisa e Desenvolvimento de } \\
\text { intangíveis não mostraram } \\
\text { significância no } \\
\text { analisado. }\end{array}$ \\
\hline $\begin{array}{l}\text { Avelino, } \\
\text { Pinheiro } \\
\text { Lamounier } \\
(2012)\end{array}$ & $\begin{array}{l}\text { Revista } \\
\text { Contabilidade } \\
\text { Organizações, Ribeirão } \\
\text { Preto. }\end{array}$ & $\begin{array}{l}\text { Apresentar um índice de } \\
\text { evidenciação de ativos } \\
\text { intangíveis, observando os } \\
\text { critérios do CPC 04 (R1). } \\
\text { Foram analisadas empresas da } \\
\text { carteira teórica do Ibovespa } \\
\text { em } 2011 \text {. }\end{array}$ & $\begin{array}{l}\text { Os autores observaram que } \\
\text { nenhuma das companhias } \\
\text { estudadas } \\
\text { completamente a determinação } \\
\text { do CPC } 04 \text { (R1). Entretanto, } \\
\text { destaca-se que alguns itens } \\
\text { importantes de evidenciação já } \\
\text { são referenciados pelas empresas } \\
\text { do estudo. Os gastos com } \\
\text { pesquisa e desenvolvimento } \\
\text { apresentou menor índice de } \\
\text { evidenciação. }\end{array}$ \\
\hline $\begin{array}{l}\text { Santos et al. } \\
(2012)\end{array}$ & $\begin{array}{l}\text { Revista Adm } \\
\text { Made, Rio de Janeiro. }\end{array}$ & $\begin{array}{lrr}\text { Buscam } & \text { analisar } & \text { a } \\
\text { evidenciação em relação aos } \\
\text { ativos intangíveis nas } \\
\text { empresas industriais mais } \\
\text { inovadoras no ano de 2008. }\end{array}$ & $\begin{array}{l}\text { As empresas analisadas } \\
\text { apresentaram informações a } \\
\text { respeito dos ativos intangíveis } \\
\text { nas suas demonstrações. Com os } \\
\text { gastos com pesquisa e } \\
\text { desenvolvimento, os autores } \\
\text { constaram que } 52,3 \% \text { das } \\
\text { empresas divulgaram esta } \\
\text { informação, reconhecendo estes } \\
\text { valores como despesa do período. }\end{array}$ \\
\hline $\begin{array}{l}\text { Beuren, } \\
\text { Theiss } \\
\text { Santana } \\
(2013)\end{array}$ & $\begin{array}{l}\text { Revista Contabilidade, } \\
\text { Gestão e } \\
\text { Governança, Brasília. }\end{array}$ & $\begin{array}{l}\text { Examinar } \text { se } r \text { há } \\
\text { conservadorismo contábil no } \\
\text { reconhecimento de ativos } \\
\text { intangíveis em fase de } \\
\text { pesquisa e desenvolvimento } \\
\text { nos anos de } 2009 \text { e } 2010 \text { das } \\
\end{array}$ & $\begin{array}{l}\text { Os autores observaram que as } \\
\text { empresas analisadas se mostram } \\
\text { conservadoras ao reconhecer os } \\
\text { ativos intangíveis nas fases de } \\
\text { pesquisa e desenvolvimento. }\end{array}$ \\
\hline
\end{tabular}


Características da Evidenciação da Fase de Pesquisa e Desenvolvimento de Ativos Intangíveis nas Companhias de Capital Aberto Brasileiras

\begin{tabular}{|c|c|c|c|}
\hline & & $\begin{array}{l}\text { empresas listadas na } \\
\text { BM\&FBovespa. }\end{array}$ & \\
\hline $\begin{array}{l}\text { Canella } \\
(2013)\end{array}$ & $\begin{array}{lr}13^{\circ} \text { Congresso } & \text { USP } \\
\text { Controladoria } & \mathrm{e} \\
\text { Contabilidade, } & \text { São } \\
\text { Paulo. } & \end{array}$ & $\begin{array}{l}\text { Buscar e examinar } \\
\text { percepção de profissionais da } \\
\text { contabilidade do setor de } \\
\text { Petróleo em relação ao } \\
\text { tratamento contábil dos gastos } \\
\text { com pesquisa } \\
\text { desenvolvimento, no ano de } \\
2013 \text {. }\end{array}$ & $\begin{array}{l}\text { Os autores puderam ver que os } \\
\text { profissionais contábeis } \\
\text { concordam com a orientação em } \\
\text { relação aos ativos intangíveis, } \\
\text { apesar de haver algumas críticas. }\end{array}$ \\
\hline $\begin{array}{l}\text { Rodrigues, } \\
\text { Elias } \\
\text { Campos } \\
(2014)\end{array}$ & $\begin{array}{lr}14^{\circ} \quad \text { Congresso } & \text { USP } \\
\text { Controladoria } & \mathrm{e} \\
\text { Contabilidade, } & \text { São } \\
\text { Paulo. } & \end{array}$ & $\begin{array}{l}\text { Verificar, no período de } 2003 \\
\text { e 2012, qual é o grau de } \\
\text { relevância a respeito da } \\
\text { informação contábil com } \\
\text { gastos de pesquisa } \mathrm{e} \\
\text { desenvolvimento } \\
\text { empresas nas } \\
\text { BM\&FBovespa. }\end{array}$ & 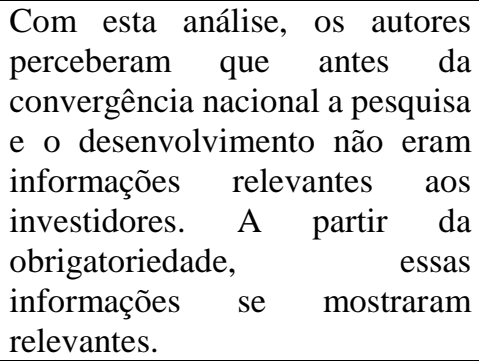 \\
\hline $\begin{array}{l}\text { Moura e } \\
\text { Varela (2014) }\end{array}$ & $\begin{array}{l}\text { Revista } \\
\text { Administração, } \\
\text { Contabilidade } \\
\text { Economia } \\
\text { (Race), Joaçaba. }\end{array}$ & $\begin{array}{l}\text { Os autores buscaram observar } \\
\text { o grau de conformidade das } \\
\text { informações publicadas } \\
\text { acerca dos ativos intangíveis. } \\
\text { Foram analisadas } 260 \\
\text { empresas da BMF\&Bovespa } \\
\text { no ano de } 2009 \text {. }\end{array}$ & $\begin{array}{l}\text { Os autores concluíram que } 75 \% \\
\text { das empresas evidenciam os seus } \\
\text { ativos intangíveis. As empresas } \\
\text { com maiores parcelas de } \\
\text { intangíveis mostraram maior } \\
\text { conformidade de evidenciação } \\
\text { obrigatória. Dos gastos com } \\
\text { pesquisa e desenvolvimento, } 38 \\
\text { das } 260 \text { empresas evidenciaram } \\
\text { este aspecto }(15 \%) \text {. }\end{array}$ \\
\hline $\begin{array}{l}\text { Silva Filho et } \\
\text { al (2014) }\end{array}$ & $\begin{array}{l}\text { Revista } \\
\text { Contexto, Porto Alegre. }\end{array}$ & $\begin{array}{l}\text { Observar se houve oscilação } \\
\text { na evidenciação dos ativos } \\
\text { intangíveis em } 213 \text { empresas } \\
\text { da BM\&FBovespa após a } \\
\text { adoção das normas } \\
\text { internacionais } \\
\text { contabilidade, durante os anos } \\
\text { de } 2009 \text { a 2011. }\end{array}$ & $\begin{array}{l}\text { Após a análise, os autores } \\
\text { puderam concluir que houve } \\
\text { aumento no reconhecimento dos } \\
\text { ativos intangíveis. }\end{array}$ \\
\hline $\begin{array}{l}\text { Nogueira e } \\
\text { Cunha }(2015)\end{array}$ & $\begin{array}{ll}9^{\circ} & \text { Congresso } \\
\text { ANPCONT, Curitiba. }\end{array}$ & $\begin{array}{l}\text { Averiguar quais são os ativos } \\
\text { intangíveis divulgados pelas } \\
\text { empresas da BM\&FBovespa } \\
\text { por setores no ano de } 2013 \text {, } \\
\text { buscando verificar se possuem } \\
\text { diferenças entre estas. }\end{array}$ & $\begin{array}{l}\text { Neste estudo, os autores } \\
\text { analisaram que a composição dos } \\
\text { ativos intangíveis está entre } 7 \% \text { e } \\
24 \% \text { do ativo total das empresas. }\end{array}$ \\
\hline $\begin{array}{l}\text { Souza, Costa e } \\
\text { Clemente } \\
(2016)\end{array}$ & $\begin{array}{lr}10^{\circ} & \text { Congresso } \\
\text { ANPCONT, } & \text { Ribeirão } \\
\text { Preto. } & \end{array}$ & $\begin{array}{l}\text { Averiguar os efeitos da } \\
\text { regulação em decorrência do } \\
\text { nível com gastos com } \\
\text { pesquisa e desenvolvimento a } \\
\text { partir da aplicação de um } \\
\text { modelo econométrico, } \\
\text { analisando empresas que } \\
\text { evidenciaram estes gastos no } \\
\text { período de 2009 a 2012. }\end{array}$ & $\begin{array}{l}\text { Os autores conseguiram perceber } \\
\text { que as empresas dos setores de } \\
\text { bens industriais são as que mais } \\
\text { destinam recursos aos ativos } \\
\text { intangíveis } \\
\text { internamente, seguidas das } \\
\text { empresas de tecnologia da } \\
\text { informação e utilidade pública. }\end{array}$ \\
\hline
\end{tabular}

Fonte: Elaborado pelos autores.

Em relação ao ativo gerado internamente, Rodrigues, Elias e Campos (2014) trouxeram que antes da convergência internacional a divulgação desta classe não era relevante. Nas pesquisas de Santos et al. (2012) e Moura e Varela (2014), a representatividade da divulgação 
com pesquisa e desenvolvimento representam, respectivamente, $15 \%$ e $52,3 \%$ dos ativos intangíveis evidenciados nas empresas estudadas.

Nos estudos de Moura e Varela (2014) e Nogueira e Cunha (2015) foi verificado que alguns setores se destacam no nível de evidenciação contábil, nos quais se pode notar que grande parte das empresas estudadas apresenta grau relevante de divulgação em relação ao grupo de intangíveis. Contudo, quando se trata de intangíveis gerados internamente, cabe destacar que algumas pesquisas indicaram que os mesmos não estão sendo evidenciados de maneira plena. Em adição, a pesquisa de Souza, Costa e Clemente (2016) demonstrou que as empresas pertencentes aos setores de Bens Industriais são as que mais apresentam divulgação a respeito dos ativos gerados internamente.

\section{METODOLOGIA DA PESQUISA}

\subsection{DELINEAMENTO DA PESQUISA}

Quanto à abordagem do problema essa pesquisa se enquadra como qualitativa. No que compete aos objetivos, classifica-se como descritiva. Os dados para a realização do presente trabalho foram obtidos por meio das Demonstrações Financeiras Padronizadas (DFPs) e notas explicativas, do período de 2015, coletadas diretamente do site das companhias da amostra. Desta forma, em relação aos procedimentos de obtenção dos dados, esta pesquisa se classifica como documental utilizando documentos de segunda mão, que de acordo com Gil (2012), são aqueles que já podem ter sido analisados, como, por exemplo, os relatórios financeiros de empresas.

\subsection{POPULAÇÃO E AMOSTRA DE PESQUISA}

A escolha dos setores do presente estudo ocorreu por meio da abordagem que traz Abreu et al. (2015), que utiliza como justificativa o potencial de inovação que as empresas pertencentes de sua amostra possuem para desenvolver ativos intangíveis. O referido autor ainda justifica que a distinção dos setores visa proporcionar uma afinidade entre as empresas relacionadas com as condições econômicas, mesmo que pertençam a atividades distintas.

Haja visto o que trouxe Abreu et al. (2015), a amostra escolhida para a análise foi intencional, na qual considerou-se as companhias que apresentam uma maior probabilidade em trabalhar com ativos intangíveis e que os possuem. Os setores selecionados para este estudo 
foram: tecnologia da informação, química, telecomunicações, bens industriais e saúde, este último enquadra os segmentos de medicamentos, medicamentos e outros produtos, produtos de limpeza, produtos de uso pessoal e serviços médicos hospitalares. Após a definição dos setores a serem estudados, por meio do site da Bolsa de Valores, Mercadorias e Futuros de São Paulo (BM\&FBovespa), foram encontradas 74 companhias abertas, destas levantou-se que 36 possuíam gastos com pesquisa e/ou desenvolvimento divulgados em suas notas explicativas. Dessa maneira, a amostra da pesquisa é composta por 36 companhias. O Quadro 2 apresenta a quantidade de companhias analisadas e sua respectiva divisão por setor de atuação.

\begin{tabular}{|l|c|}
\multicolumn{1}{|c|}{ Quadro 2- Amostra da pesquisa } \\
\begin{tabular}{|l|c|}
\hline \multicolumn{1}{|c|}{ Setor } & Número de Empresas \\
\hline Bens Industriais & 18 \\
\hline Química & 2 \\
\hline Tecnologia da Informação & 6 \\
\hline Telecomunicações & 3 \\
\hline Saúde & 7 \\
\hline Total & 36 \\
\hline
\end{tabular}
\end{tabular}

Fonte: Elaborado pelos autores.

Após a obtenção da amostra da pesquisa, foram analisados os dados relativos as características da evidenciação da fase de pesquisa e desenvolvimento, bem como o nível de evidenciação das mesmas.

O instrumento de coleta de dados que se refere o Quadro 2 foi validado realizando um teste de análise em 5 companhias que possuíam ativos intangíveis gerados internamente, com o propósito de constatar se o referido instrumento atenderia as questões específicas, que serão apresentadas na seção seguinte, a respeito da evidenciação dos intangíveis gerados internamente que precisam ser divulgadas conforme o CPC 04 (R1).

\subsection{PROCEDIMENTOS DA PESQUISA}

Para atingir o objetivo proposto da pesquisa, foram analisadas as DFPs e notas explicativas, relativas ao ano de 2015, das companhias componentes da amostra deste estudo. Como instrumento de coleta dos dados foi elaborada uma Lista de Verificação de acordo com os requisitos previstos pelo CPC $04(\mathrm{R} 1)$ em relação à evidenciação dos gastos com pesquisa e desenvolvimento relativo aos ativos intangíveis gerados internamente. O Quadro 3 apresenta a Lista de Verificação, que contém 8 questionamentos a respeito da divulgação dos gastos com pesquisa e desenvolvimento. 
Quadro 3 - Lista de Verificação dos Gastos com Pesquisa e Desenvolvimento

a) Evidenciou em linha específica gastos com pesquisa em sua Demonstração do Resultado do Exercício?

b) Evidenciou em Notas Explicativas a composição (detalhamento) dos gastos com pesquisa?

c) Realiza a separação dos gastos com pesquisa e desenvolvimento conforme determina o CPC 04 $(\mathrm{R} 1)$ ?

d) Evidenciou em Notas Explicativas quais gastos com pesquisa efetivamente foi desenvolvido/ou está em desenvolvimento determinado ativo intangível?

e) Divulgou qual (is) ativo (s) ela espera que resulte da (s) pesquisa (s) realizada (s)?

f) Qual o tratamento contábil conferido aos gastos na fase de desenvolvimento? Despesa ou reconheceu no ativo como Intangível em Desenvolvimento?

g) Se registrado no Intangível, demonstrou como este intangível irá gerar benefícios econômicos futuros?

h) Evidenciou em Notas Explicativas a composição dos custos relativos à fase de desenvolvimento?

Fonte: Elaborado pelos autores com base no CPC 04 (R1, 2010)

A Lista de Verificação, demonstrada no Quadro 3, é o instrumento de pesquisa que auxiliou a obtenção dos dados relativos as características da evidenciação realizada pelas companhias no que tange aos gastos com pesquisa e desenvolvimento dos ativos intangíveis gerados internamente.

A partir da obtenção dos dados coletados nas DFPs e notas explicativas, foram tabuladas as informações e apresentadas as características de evidenciação das fases de pesquisa e desenvolvimento nas companhias pertencentes da amostra analisada.

Para a mensuração do nível de evidenciação utilizou-se a seguinte metodologia: para as companhias que evidenciaram os itens da Lista de Verificação, foi atribuído valor 1; e nos casos em que ela não divulgou o respectivo item, atribuiu-se 0. Dessa maneira, o nível de evidenciação foi calculado dividindo-se a quantidade de itens divulgados pela companhia pelo total de itens da Lista de Verificação.

Além do objetivo principal proposto de relatar as características da evidenciação das empresas, também foi realizada uma análise na qual foram comparados os resultados por setor de atuação. A apresentação dos resultados da pesquisa foi por meio de Tabelas.

\section{APRESENTAÇÃO E ANÁLISE DOS RESULTADOS}

Nesta seção estão apresentados os resultados do estudo e posteriormente analisados. Em um primeiro momento estão demonstrados os números relacionados à evidenciação por setor 
de atuação e posteriormente a evidenciação pertinente a cada item da Lista de Verificação apresentada na seção de Metodologia.

\subsection{MÉDIA DE EVIDENCIAÇÃO POR SETOR}

$\mathrm{Na}$ Tabela 1 estão apresentados os resultados relativos à média do nível de evidenciação verificada em cada setor de atuação analisados nesta pesquisa.

Tabela 1: Média do nível de evidenciação por setor

\begin{tabular}{l|c}
\hline \multicolumn{1}{c|}{ Setor } & Média do Nível de Evidenciação \\
\hline Bens Industriais & $24,31 \%$ \\
\hline Química & $18,75 \%$ \\
\hline Tecnologia da Informação & $31,25 \%$ \\
\hline Telecomunicações & $12,50 \%$ \\
\hline Saúde & $25,00 \%$ \\
\hline Média Geral & $24,31 \%$ \\
\hline
\end{tabular}

Fonte: Elaborado pelos autores com base nos dados da pesquisa.

Com base na Tabela 1 é possível perceber que o setor que apresenta maior média em relação ao nível de evidenciação dos gastos com pesquisa e desenvolvimento é o de Tecnologia da Informação, sendo este o terceiro setor com mais empresas estudadas. Comparando com o estudo de Souza, Costa e Clemente (2016), os resultados divergem, visto que os autores contataram que o setor que apresentou maior média de evidenciação dos gastos com pesquisa e desenvolvimento foi o de Bens Industriais, seguido do setor de Tecnologia da Informação que ficou na $2^{\mathrm{a}}$ colocação no ranking de maiores médias de nível de evidenciação. Dessa forma, apesar dos resultados diferirem, o fato do setor de Tecnologia da Informação constar na $2^{\mathrm{a}}$ colocação quanto a média de nível de evidenciação, o coloca também em boa posição, o que pode sugerir uma tendência do setor.

No geral, a média do nível de evidenciação englobando todos os setores apresentou $24,31 \%$, o que demonstra que a evidenciação dos gastos com intangíveis gerados internamente ainda é baixa no Brasil. Estes resultados corroboram com os estudos de Avelino, Pinheiro e Lamounier (2012) e Moura e Varela (2014), que apresentaram que a evidenciação com relação aos gastos de pesquisa e desenvolvimento não demonstra índice elevado.

\subsection{RESULTADOS POR ITEM DE EVIDENCIAÇÃO}


Nesta seção está abordado o percentual de evidenciação de cada item apresentado na Lista de Verificação, com a finalidade identificar as características da evidenciação da fase de pesquisa e desenvolvimento de ativos intangíveis nas companhias de capital aberto brasileiras. Na Tabela 2 está demonstrado os resultados do item "a" da Lista de Verificação, que remete a evidenciação em linha específica dos gastos com pesquisa na Demonstração do Resultado do Exercício (DRE) das companhias.

Tabela 2: Evidenciação em linha específica dos gastos com pesquisa em sua Demonstração do Resultado do Exercício.

\begin{tabular}{l|c|c|c}
\hline \multicolumn{1}{c|}{ Setor } & $\begin{array}{c}\text { Total de } \\
\text { Companhias }\end{array}$ & $\begin{array}{c}\text { Quantidade que } \\
\text { evidenciou o item }\end{array}$ & $\begin{array}{c}\% \text { de } \\
\text { evidenciação }\end{array}$ \\
\hline Bens Industriais & 18 & 5 & $27,78 \%$ \\
\hline Química & 2 & 1 & $50,00 \%$ \\
\hline Tecnologia da Informação & 6 & 4 & $66,67 \%$ \\
\hline Telecomunicações & 3 & 0 & $0,00 \%$ \\
\hline Saúde & 7 & 1 & $14,29 \%$ \\
\hline Média Geral & 36 & 11 & $30,56 \%$ \\
\hline
\end{tabular}

Fonte: Elaborado pelos autores com base nos dados da pesquisa.

Através da Tabela 2 pode-se notar que o setor de Tecnologia da Informação apresentou em sua DRE maior percentual de evidenciação em relação à divulgação dos gastos com pesquisa, das 6 empresas estudadas 4 apresentaram este item. É importante salientar que algumas empresas, em suas notas explicativas e também no relatório da administração, apresentavam informações a respeito de gastos com pesquisa, mas não especificavam em qual grupo da DRE estes gastos foram alocados. A Tabela 3 expõe o percentual de evidenciação em notas explicativas do detalhamento dos gastos com pesquisa.

Tabela 3: Evidenciação em Notas Explicativas sobre a composição (detalhamento) dos gastos com pesquisa

\begin{tabular}{l|c|c|c}
\hline \multicolumn{1}{c|}{ Setor } & $\begin{array}{c}\text { Total de } \\
\text { Companhias }\end{array}$ & $\begin{array}{c}\text { Quantidade que } \\
\text { evidenciou o item }\end{array}$ & $\begin{array}{c}\% \text { de } \\
\text { evidenciação }\end{array}$ \\
\hline Bens Industriais & 18 & 5 & $27,78 \%$ \\
\hline Química & 2 & 2 & $100,00 \%$ \\
\hline Tecnologia da Informação & 6 & 2 & $33,33 \%$ \\
\hline Telecomunicações & 3 & 0 & $0,00 \%$ \\
\hline Saúde & 7 & 1 & $14,29 \%$ \\
\hline Média Geral & 36 & 10 & $27,78 \%$ \\
\hline
\end{tabular}

Fonte: Elaborado pelos autores com base nos dados da pesquisa.

Apesar de ter maior evidenciação dos gastos com pesquisa em linha específica na DRE, o setor de Tecnologia da Informação não manteve o mesmo nível em relação ao item de composição dos gastos com pesquisa. Detalhe importante para o setor de Química, que nas duas 
empresas estudadas apresentou o detalhamento destes gastos, mesmo com uma das companhias não apresentando a linha na qual estes gastos estão alocados na DRE. A Tabela 4 expõe o percentual de empresas que separam os gastos com pesquisa dos gastos de desenvolvimento.

Tabela 4: Evidenciação da separação dos gastos com pesquisa e desenvolvimento conforme determina o CPC 04 (R1)

\begin{tabular}{l|c|c|c}
\hline \multicolumn{1}{c|}{ Setor } & $\begin{array}{c}\text { Total de } \\
\text { Companhias }\end{array}$ & $\begin{array}{c}\text { Quantidade que } \\
\text { evidenciou o item }\end{array}$ & $\begin{array}{c}\% \text { de } \\
\text { evidenciação }\end{array}$ \\
\hline Bens Industriais & 18 & 1 & $5,56 \%$ \\
\hline Química & 2 & 0 & $0,00 \%$ \\
\hline Tecnologia da Informação & 6 & 1 & $16,67 \%$ \\
\hline Telecomunicações & 3 & 0 & $0,00 \%$ \\
\hline Saúde & 7 & 0 & $0,00 \%$ \\
\hline Média Geral & 36 & 2 & $5,56 \%$ \\
\hline
\end{tabular}

Fonte: Elaborado pelos autores com base nos dados da pesquisa.

O item "c" da Lista de Verificação remete a separação dos gastos dos ativos intangíveis gerados internamente, nas fases de pesquisa e desenvolvimento, e apenas duas empresas do total das analisadas evidenciam em separado. O CPC 04 (R1, 2010) determina que quando o gasto com desenvolvimento não é diferenciado da fase de pesquisa, este deve ser tratado como gasto de pesquisa, entretanto analisando as DFPs das companhias da amostra, foi possível perceber que a maioria não utiliza a nomenclatura adequada para estes gastos. Na Tabela 5 estão retratados os resultados relacionados ao percentual das empresas que divulgaram se os gastos com pesquisa foram desenvolvidos ou estão em desenvolvimento de determinado ativo intangível.

Tabela 5: Evidenciação em Notas Explicativas dos gastos com pesquisa que foram desenvolvidos/ou estão desenvolvendo determinado ativo intangível

\begin{tabular}{l|c|c|c}
\hline \multicolumn{1}{c|}{ Setor } & $\begin{array}{c}\text { Total de } \\
\text { Companhias }\end{array}$ & $\begin{array}{c}\text { Quantidade que } \\
\text { evidenciou o item }\end{array}$ & $\begin{array}{c}\% \text { de } \\
\text { evidenciação }\end{array}$ \\
\hline Bens Industriais & 18 & 1 & $5,56 \%$ \\
\hline Química & 2 & 0 & $0,00 \%$ \\
\hline Tecnologia da Informação & 6 & 0 & $0,00 \%$ \\
\hline Telecomunicações & 3 & 0 & $0,00 \%$ \\
\hline Saúde & 7 & 0 & $0,00 \%$ \\
\hline Média Geral & 36 & 1 & $2,78 \%$ \\
\hline
\end{tabular}

Fonte: Elaborado pelos autores com base nos dados da pesquisa.

De acordo com a Tabela 5, conclui-se que não é uma prática das companhias divulgarem se o projeto da pesquisa foi ou não efetivamente desenvolvido, os resultados demonstraram que apenas uma companhia das 36 estudadas enfatizou este ponto em suas notas explicativas. Esta situação denota uma característica que precisa melhorar na evidenciação realizada acerca dos 
intangíveis gerados internamente na amostra analisada. Na Tabela 6 têm-se o resultado percentual das companhias que divulgam os ativos que esperam da pesquisa realizada.

Tabela 6: Evidenciação do (s) ativo (s) que a companhia espera que resulte da (s) pesquisa (s) realizada $(\mathrm{s})$

\begin{tabular}{l|c|c|c}
\hline \multicolumn{1}{c|}{ Setor } & $\begin{array}{c}\text { Total de } \\
\text { Companhias }\end{array}$ & $\begin{array}{c}\text { Quantidade que } \\
\text { evidenciou o item }\end{array}$ & $\begin{array}{c}\% \text { de } \\
\text { evidenciação }\end{array}$ \\
\hline Bens Industriais & 18 & 2 & $11,11 \%$ \\
\hline Química & 2 & 0 & $0,00 \%$ \\
\hline Tecnologia da Informação & 6 & 0 & $0,00 \%$ \\
\hline Telecomunicações & 3 & 0 & $0,00 \%$ \\
\hline Saúde & 7 & 0 & $0,00 \%$ \\
\hline Média Geral & 36 & 2 & $5,56 \%$ \\
\hline
\end{tabular}

Fonte: Elaborado pelos autores com base nos dados da pesquisa.

Com relação à evidenciação do intangível que a empresa espera que resulte da pesquisa, $5,56 \%$ do total da amostra divulgaram esta informação, o que representa apenas duas empresas, ambas do setor de Bens Industriais. Vale mencionar também, a baixa ocorrência de evidenciação desta informação por parte da amostra analisada. Na Tabela 7, está apresentado a seguir o tratamento que as companhias utilizam em relação aos gastos na fase de desenvolvimento.

Tabela 7: Evidenciação do tratamento contábil conferido aos gastos na fase de desenvolvimento: Despesa ou Intangível em desenvolvimento

\begin{tabular}{l|c|c|c}
\hline \multicolumn{1}{c|}{ Setor } & $\begin{array}{c}\text { Total de } \\
\text { Companhias }\end{array}$ & $\begin{array}{c}\text { Quantidade que } \\
\text { evidenciou o item }\end{array}$ & $\begin{array}{c}\% \text { de } \\
\text { evidenciação }\end{array}$ \\
\hline Bens Industriais & 18 & 13 & $72,22 \%$ \\
\hline Química & 2 & 0 & $0,00 \%$ \\
\hline Tecnologia da Informação & 6 & 4 & $66,67 \%$ \\
\hline Telecomunicações & 3 & 3 & $100,00 \%$ \\
\hline Saúde & 7 & 6 & $85,71 \%$ \\
\hline Média Geral & 36 & 26 & $72,22 \%$ \\
\hline
\end{tabular}

Fonte: Elaborado pelos autores com base nos dados da pesquisa.

Em conformidade com o exposto na Tabela 7, percebe-se que o item que apresentou maior nível de evidenciação na amostra foi relacionado ao tratamento conferido aos gastos com desenvolvimento de ativos intangíveis. Neste item, os setores apresentaram grau elevado de evidenciação, com exceção do setor de Química, que não teve nenhuma das suas empresas divulgando tal informação. $\mathrm{O}$ tratamento mais utilizado pelas companhias foi a classificação destes gastos com desenvolvimento como ativo intangível. Na Tabela 8 aponta-se os percentuais relativos à evidenciação de como o intangível em desenvolvimento irá gerar benefícios econômicos futuros. 
Características da Evidenciação da Fase de Pesquisa e Desenvolvimento de Ativos Intangíveis nas Companhias de Capital Aberto Brasileiras

Tabela 8: Evidenciação de como o intangível irá gerar benefícios econômicos futuros

\begin{tabular}{l|c|c|c}
\multicolumn{1}{c|}{ Setor } & $\begin{array}{c}\text { Total de } \\
\text { Companhias }\end{array}$ & $\begin{array}{c}\text { Quantidade que } \\
\text { evidenciou o item }\end{array}$ & $\begin{array}{c}\% \text { de } \\
\text { evidenciação }\end{array}$ \\
\hline Bens Industriais & 18 & 6 & $33,33 \%$ \\
\hline Química & 2 & 0 & $0,00 \%$ \\
\hline Tecnologia da Informação & 6 & 1 & $16,67 \%$ \\
\hline Telecomunicações & 3 & 0 & $0,00 \%$ \\
\hline Saúde & 7 & 3 & $42,86 \%$ \\
\hline Média Geral & 36 & 10 & $27,78 \%$ \\
\hline
\end{tabular}

Fonte: Elaborado pelos autores com base nos dados da pesquisa.

Apesar do grau elevado de empresas que apresentaram o tratamento contábil conferido aos gastos na fase de desenvolvimento de ativos intangíveis, o mesmo não foi mantido no item que busca mostrar se as empresas demonstram os aspectos que provam que o ativo intangível irá gerar benefícios econômicos futuros, conforme aborda o CPC 04 (R1). Das companhias que possuem ativos intangíveis gerados internamente, somente 10 certificaram a maneira de geração de benefícios econômicos esperada dos mesmos. Na Tabela 9 exibe-se a evidenciação dos custos relativos à fase de desenvolvimento.

Tabela 9: Evidenciação em Notas Explicativas sobre composição dos custos relativos à fase de desenvolvimento

\begin{tabular}{l|c|c|c}
\hline \multicolumn{1}{c|}{ Setor } & $\begin{array}{c}\text { Total de } \\
\text { Companhias }\end{array}$ & $\begin{array}{c}\text { Quantidade que } \\
\text { evidenciou o item }\end{array}$ & $\begin{array}{c}\text { \% de } \\
\text { evidenciação }\end{array}$ \\
\hline Bens Industriais & 18 & 2 & $11,11 \%$ \\
\hline Química & 2 & 0 & $0,00 \%$ \\
\hline Tecnologia da Informação & 6 & 3 & $50,00 \%$ \\
\hline Telecomunicações & 3 & 0 & $0,00 \%$ \\
\hline Saúde & 7 & 3 & $42,86 \%$ \\
\hline Média Geral & 36 & 8 & $22,22 \%$ \\
\hline
\end{tabular}

Fonte: Elaborado pelos autores com base nos dados da pesquisa.

Por fim, analisou-se se as companhias componentes da amostra apresentavam a composição dos custos na fase de desenvolvimento. Os resultados demonstram que grande parte das empresas não divulgaram o detalhamento das informações a respeito dos custos relativos aos gastos com desenvolvimento de ativos intangíveis.

O setor de Tecnologia da Informação apresentou 50\% de evidenciação, enquanto o setor de Bens Industrias, o que possui maior número de empresas que compõe a amostra, divulgou apenas $11,11 \%$, o que corresponde a apenas 3 empresas do total de 18 que formam o setor analisado.

Levando em consideração as informações resultantes das análises realizadas no que tange a divulgação sobre os ativos intangíveis gerados internamente, em comparação aos resultados 
da pesquisa de Avelino, Pinheiro e Lamounier (2012) nota-se uma semelhança, visto que o mesmo demonstrou que as empresas, na maior parte dos casos, somente fazem menção aos gastos com pesquisa e desenvolvimento no Relatório da Administração, não demonstrando os montantes reconhecidos como despesa do período, o que ressalta a baixa divulgação em notas explicativas. Em consonância, o estudo de Moura e Varela (2014), também apresentou nos seus resultados um baixo nível de divulgação em relação aos intangíveis gerados internamente.

Esse baixo nível de evidenciação constatado nas pesquisas brasileiras, pode estar relacionado às dúvidas das companhias referentes a compreensão do CPC 04 (R1), desta forma, estes resultados chamam atenção para o monitoramento dos órgãos normalizadores e reguladores quanto ao atendimento das normas por parte das companhias.

\section{CONCLUSÃO}

Foi possível observar que as características de evidenciação da fase de pesquisa e desenvolvimento de ativos intangíveis gerados internamente são destacadas pelo baixo índice de divulgação destas informações. Constata-se que pouco são divulgados os detalhamentos e composição destes gastos. A este respeito, ressalta-se o baixo índice com relação aos seguintes pontos: i) qual intangível as companhias esperam que sejam desenvolvidos a partir das pesquisas realizadas; ii) como o desenvolvimento dos intangíveis irá gerar benefícios econômicos futuros; e iii) evidenciação da separação dos gastos com pesquisa e desenvolvimento.

Diante do exposto, pode-se inferir que as companhias abertas estudadas pouco evidenciam informações relacionadas aos intangíveis gerados internamente, sendo precária a divulgação das mesmas. Esta pesquisa corrobora com o estudo de Avelino, Pinheiro e Lamounier (2012), em que foi constatado que nenhuma das empresas apresentou completamente a evidenciação de acordo com o CPC 04 (R1).

Fazendo uma análise comparativa com a pesquisa de Souza, Costa e Clemente (2016) que apresentou o setor de Bens Industriais com maior evidenciação dos gastos com ativos intangíveis gerados internamente, pode-se notar divergências nos resultados pois na amostra do presente estudo o setor com maior evidenciação foi o de Tecnologia da Informação.

Realizando um cotejamento com o estudo de Moura e Varela (2014), que obteve o resultado que o nível de evidenciação das empresas é de $15 \%$, pode-se notar que os resultados não se distanciaram muito, visto que se obteve nesta pesquisa um nível médio de evidenciação de $24,31 \%$, o que demonstra que a divulgação dos gastos com ativos intangíveis gerados 
internamente ainda é deficiente no Brasil. Estes resultados alertam para um possível problema de evidenciação, na concepção de Canella (2013), para proporcionar um melhor entendimento das mudanças que ocorrem com os ativos intangíveis com passar do tempo, é necessária uma melhor divulgação destes ativos.

Este estudo contribui para a literatura brasileira científica no que tange aos conhecimentos técnicos acerca da evidenciação dos ativos intangíveis gerados internamente, demonstrando como estão sendo realizadas tais evidenciações a respeito destes ativos. Ressalta-se que os resultados desta pesquisa se limitam a amostra analisada e período abrangido, não podendo ser generalizados para outras empresas ou períodos diferentes.

Como sugestão para estudos futuros, seria interessante analisar uma série temporal visando identificar a evolução na evidenciação dos gastos com pesquisa e desenvolvimento, bem como identificar características relacionadas ao nível de evidenciação destes gastos ao longo dos anos por meio de uma análise estatística.

\section{REFERÊNCIAS}

ABREU, E. S.; BRUNI, A. L.; GOMES, S. M. S.; PAIXÃO, R. B. Relações entre inovação tecnológica e estrutura de capital: um estudo de empresas brasileiras de capital aberto. Revista de Administração e Inovação, São Paulo, v. 12, n. 1, p.326-350, 2015. Disponível em: $<$ http://www.spell.org.br/documentos/ver/34956/relacoes-entre-inovacao-tecnologica-eestrutura-de-capital--um-estudo-de-empresas-brasileiras-de-capital-aberto/i/pt-br>. Acesso em: 28 jul. 2016.

AVELINO, B. C.; PINHEIRO, L. E. T.; LAMOUNIER, W. M. Evidenciação de ativos intangíveis: Estudo empírico em companhias abertas. Revista de Contabilidade e Organizações, Ribeirão Preto, v. 6, n. 14, p.23-45, 1 abr. 2012. Universidade de Sao Paulo Sistema Integrado de Bibliotecas - SIBiUSP. http://dx.doi.org/10.11606/rco.v6i14.45399. Disponível em: <http://www.revistas.usp.br/rco/article/view/45399>. Acesso em: 17 ago. 2016.

BEUREN, I. M.; ANGONESE, R. Instrumentos para determinação do índice de evidenciação de informações contábeis. Revista Eletrônica de Estratégica \& Negócios, Florianópolis, v. 8, n. 1, p.120-144, jan. 2015.

BEUREN, I. M. (Org); LONGARAY, A. A.; RAUPP, F. M.; SOUSA, M. A. B.; COLAUTO, R. D.; PORTON, R. A. B. Como elaborar trabalhos monográficos em contabilidade: Teoria e Prática. 3. ed. São Paulo: Atlas, 2013.

BEUREN, I. M.; THEISS, V.; SANT'ANA, S. V. Conservadorismo Contábil no Reconhecimento de Ativos Intangíveis em Fase de Pesquisa e Desenvolvimento: um estudo em empresas da BM\&FBovespa; Contabilidade, Gestão e Governança, Brasília, v. 16, n. 1, p.98111 , jan/abr. 2013. 
CANELLA, C. J. Percepções de profissionais da contabilidade do setor de petróleo sobre o tratamento contábil dos gastos com pesquisa e desenvolvimento. In: CONGRESSO USP CONTROLADORIA E CONTABILIDADE, 13., 2013, São Paulo. Anais... . São Paulo: USP, 2012.

CARLOS FILHO, F. A.; LAGIOIA, U. C. T.; MONTEIRO, J. A. M.; SILVA FILHO, L. L.; ARAUJO, J. G.; ARAÚJO, J. G. N. Importância e Contribuição do Ativo Intangível: Percepção dos Empreendedores de Micro e Pequenas Empresas Sobre o Capital Intelectual. Revista Organizações em Contexto, São Bernardo do Campo, v. 10, n. 20, p.1-27, 2014. Disponível em: <https://www.metodista.br/revistas/revistas-ims/index.php/OC/article/view/4448>. Acesso em: 30 jul. 2016.

COVA, C. J. G. A Adoção das IFRS no Brasil e o Fortalecimento das Boas Práticas de Governança Corporativa. Pensar Contábil, Rio de Janeiro, v. 10, n. 42, p.22-30, out/dez. 2008.

COMITÊ DE PRONUNCIAMENTOS CONTÁBEIS (CPC). Pronunciamento Técnico CPC 04 (R1) - Ativo Intangível, 2010. Disponível em: <http://www.cpc.org.br/CPC/DocumentosEmitidos/Pronunciamentos/Pronunciamento? Id=35>. Acesso em: 30 jul. 2016.

DAHMASH, F. N.; DURAND, R. B.; WATSON, John. The value relevance and reliability of reported goodwill and identifiable intangible assets. The British Accounting Review, v. 41, p. 120-137, 2009.

GIL, A. C. Métodos e técnicas de pesquisa social. 6. ed. São Paulo: Atlas, 2012.

HENDRIKSEN, E. S.; VAN BREDA, M. F. Teoria da Contabilidade. 5. ed. São Paulo: Atlas, 2010.

HOSS, O.; ROJO, C. A.; GRAPEGGIA, M. Gestão de Ativos Intangíveis: Da mensuração à competitividade por cenários. São Paulo: Atlas, 2010.

IUDÍCIBUS, S. Teoria da Contabilidade.11. ed. São Paulo: Atlas, 2015.

MARTINS, E.; GELBCKE, E. R.; SANTOS, A.; IUDÍCIBUS, S. Manual de Contabilidade Societária: Aplicável a todas as sociedades. 2. ed. São Paulo: Atlas, 2013.

MOURA, G. D.; VARELA, P. S. Análise da conformidade das informações divulgadas sobre ativos intangíveis em empresas listadas na BM\&FBovespa;. Race, Joaçaba, v. 13, n. 2, p.637662, maio/ago. 2014.

NOGUEIRA, M. B.; CUNHA, M. F. Uma análise da divulgação e composição do ativo intangível das empresas listadas na BM\&FBovespa; por setor no Brasil. In: CONGRESSO ANPCONT, 9., 2015, Curitiba. Anais... Curitiba: Anpcont, 2015.

OLIVEIRA, L.; RODRIGUES, L. L.; CRAIG, R. Intangible assets and value relevance: evidence from the Portuguese stock exchange. The British Accounting Review, v. 42, p. 241$252,2010$. 
PEIXOTO, F.; MALAQUIAS, R. F. O impacto da convergência contábil na evidenciação dos instrumentos financeiros derivativos das empresas brasileiras. Revista de Gestão, Salvador, v. 2, n. 1, p.39-55, jan/abr. 2012.

RODRIGUES, J. M.; ELIAS, W. G.; CAMPOS, E. S. Relevância da Informação Contábil: uma análise dos efeitos da contabilização dos gastos com pesquisa e desenvolvimento com a aplicação da Lei 11.638/07 no mercado brasileiro. In: CONGRESSO USP CONTROLADORIA E CONTABILIDADE, 14., 2014, São Paulo. Anais... . São Paulo: 2014.

ROLIM, M. V.; LEMES, S.; TAVARES, M. Disclosure dos ativos intangíveis das empresas britânicas e a investigação da sua relação com as empresas de auditoria e os setores de atuação. Revista Ceppg, Catalão, v. 23, n. 13, p.51-82, 2010.

SANTOS, A. V. F.; XIMENES, C. G.; GALLAN, A. V.; LUCA, M. M. M. Evidenciação de ativos intangíveis nas empresas industriais mais inovadoras segundo classificação do índice Brasil de inovação (IBI). Revista Adm Made, Rio de Janeiro, v. 16, n. 1, p.1-23, jan/abr. 2012.

SCHMIDT, P.; SANTOS, J. L. Avaliação de Ativos Intangíveis. 2. ed. São Paulo: Atlas, 2009.

SILVA FILHO, L. L.; LAGIOIA, U. C. T.; CARLOS FILHO, F. A.; ARAÚJO, J. G.; LEMOS, L. V. Um estudo sobre o reflexo no reconhecimento dos ativos intangíveis após a adoção das normas internacionais de contabilidade nas empresas brasileiras listadas na BM\&FBovespa. Contexto, Porto Alegre, v. 14, n. 27, p.55-69, maio/ago 2014.

SOUZA, A. R.; COSTA, M. C.; CLEMENTE, A. Regulação e o nível dos gastos em pesquisa e desenvolvimento: uma análise das empresas listadas na BM\&FBovespa;. In: CONGRESSO ANPCONT, 10., 2016, Ribeirão Preto. Anais... Ribeirão Preto: Anpcont, 2016. 